\title{
Factors associated with lung cancer in COPD patients
}

This article was published in the following Dove Press journal: International Journal of COPD

\author{
Martin Sandelin' \\ Stéphanie Mindus' \\ Marcus Thuresson ${ }^{2}$ \\ Karin Lisspers ${ }^{3}$ \\ Björn Ställberg ${ }^{3}$ \\ Gunnar Johansson ${ }^{3}$ \\ Kjell Larsson ${ }^{4}$ \\ Christer Janson' \\ 'Department of Medical Sciences, \\ Respiratory, Allergy and Sleep \\ Research, Uppsala University, Uppsala, \\ Sweden; ${ }^{2}$ Statisticon AB, Uppsala, \\ Sweden; ${ }^{3}$ Department of Public Health \\ and Caring Science, Family Medicine \\ and Preventive Medicine, Uppsala \\ University, Uppsala, Sweden; ${ }^{4}$ Lung \\ and Allergy Research Unit, National \\ Institute of Environmental Medicine, \\ Karolinska Institute, Stockholm, \\ Sweden
}

Background: The risk of dying of lung cancer is up to eightfold higher in patients with COPD than in age- and gender-matched controls. The aim of this study was to investigate the factors associated with lung cancer in a large cohort of COPD patients from primary care centers.

Methods: To analyze whether age, gender, socioeconomic factors, comorbidity, and medication affect the risk of lung cancer in COPD, we used a COPD cohort of primary care patients. Data from primary care medical records and mandatory Swedish national registers were collected and linked in this population-based, retrospective observational registry study (NCT01146392).

Results: Of the total cohort, 19,894 patients were included in the study. Five hundred and ninety-four lung cancer cases were diagnosed, corresponding to $3.0 \%$ of the studied population. In a multivariate analysis, the risk of lung cancer was lower if the COPD patients had a concurrent asthma diagnosis (HR: 0.54, CI: 0.41-0.71), while the risk of lung cancer increased with increasing age. A decreased lung cancer risk was observed in an exposure-dependent manner in patients who were prescribed inhaled corticosteroids (HR: 0.52, CI: 0.37-0.73), while the opposite was found for the use of acetylsalicylic acid (HR: 1.58, CI: 1.15-2.16).

Conclusion: In this large population-based cohort, a concurrent asthma diagnosis and use of inhaled corticosteroids were independently related to decreased risk of lung cancer in COPD patients, while the use of acetylsalicylic acid was associated with an increased risk. The findings of the present study should be seen as hypothesis generating and need to be confirmed in prospective studies.

Keywords: asthma, NSCLC, risk factor, ACO, inhaled corticosteroids

\section{Introduction}

COPD mainly affects smokers and former smokers. ${ }^{1}$ The risk of developing COPD increases with the amount of cigarette exposure. ${ }^{2}$ It is known that the prevalence of lung cancer is significantly higher in patients with COPD than in the average nonsmoking population, reflecting the impact of cigarette smoking in both diseases. ${ }^{3}$ As an example, we previously showed that COPD patients from Swedish primary health care centers have an eight times higher risk of dying of lung cancer compared to a control group matched for age and gender. ${ }^{4}$ In a cohort of smokers or ex-smokers the OR for developing lung cancer for patients with moderate or severe COPD was 2.6 compared to mild or non-COPD patients matched for smoking habits. ${ }^{5}$

Both COPD and lung cancer are closely related to the chronic inflammation and oxidative stress induced by smoking. ${ }^{6,7}$ However, it has been shown that patients with emphysema who have never smoked also have an increased risk of developing lung cancer. ${ }^{8,9}$ Hence, it is likely that the inflammatory process driving the formation of emphysema contributes as a risk factor for lung cancer. ${ }^{10}$
Correspondence: Christer Janson Department of Medical Sciences, Respiratory, Allergy and Sleep Research, Uppsala University, SE-75I 85 Uppsala, Sweden

Tel +46 I8 611 4I 38

$\mathrm{Fax}+46$ I8 6II 0228

Email christer.janson@medsci.uu.se
International Journal of COPD 20|8:13 |833-1839 Dovepress in http://dx.doi.org// 0.21 147/COPD.SI 62484 (c) (1) (-) 2018 Sandelin et al. This work is published and licensed by Dove Medical Press Limited. The full terms of this license are available at https://www.dovepress.com/terms.php c. hereby accept the Terms. Non-commercial uses of the work are permitted without any further permission from Dove Medical Press Limited, provided the work is properly attributed. For permission for commercial use of this work, please see paragraphs 4.2 and 5 of our Terms (https://www.dovepress.com/terms.php). 
Previous studies have indicated that inhaled corticosteroids (ICS) reduce the risk of lung cancer in COPD patients and that the effect is dose-dependent. ${ }^{11,12} \mathrm{~N}$-acetylcysteine (NAC) is widely prescribed to many COPD patients and the side effects are generally thought to be limited. Recent findings in animal studies have pointed toward a new and potentially detrimental role of NAC and an increased risk of lung cancer occurrence. ${ }^{13}$ A negative association between acetylsalicylic acid and lung cancer has been found in some investigations. ${ }^{14}$

Many patients with COPD also have a diagnosis of asthma. ${ }^{15}$ To some extent this is related to the difficulty distinguishing between these two diseases, but there is also increasing evidence that both diseases may coexist. This condition has been named asthma COPD overlap (ACO). ${ }^{16}$ Other comorbidities are also common in patients suffering from COPD ${ }^{17}$ According to a study by Vanfleteren et al, the five most frequent comorbidities were hyperglycemia, atherosclerosis, hypertension, dyslipidemia, and osteoporosis. ${ }^{18}$ It has also been shown that a significantly higher proportion of COPD patients suffer from depression than non-COPD patients. ${ }^{19}$ Due to the frequent comorbidities, drugs targeting cardiovascular disease, osteoporosis, dyslipidemia, and depression are often prescribed to COPD patients.

The aim of our study was to investigate the factors associated with lung cancer in a large cohort of COPD patients in a primary care setting, with special emphasis on the role of pharmacological treatments and comorbidities.

\section{Methods}

To analyze whether comorbidity and continuous use of medication affect the risk of lung cancer development in COPD, we used a large COPD cohort of primary care patients. ${ }^{4}$

\section{Data collection}

Data from primary care medical records and mandatory Swedish national registers were collected and linked to form a population-based, retrospective, observational registry study. The linked database is kept at and maintained by the Department of Public Health and Caring Sciences, Uppsala University, Sweden. The primary health care centers from which patient data were obtained were chosen to reflect a mixture of rural and urban areas, public and private health care providers, and center sizes. However, no formal stratification of health care providers was performed. Patient data were retrieved from 76 centers that together served approximately $8 \%$ of the Swedish population.

Date of birth, gender, diagnoses according to the International Classification of Diseases, 10th revision, Clinical
Modification (ICD-10-CM) codes, number of primary health care center contacts, lung function assessments, and collections of drug prescriptions were retrieved from the primary health care centers' medical records using an established software system (Pygargus Customized eXtraction Program, CXP; Pygargus AB, Stockholm, Sweden). ${ }^{20}$ A study identification number replaced each patient's personal identification number after data were collected to ensure patient anonymity.

Additional patient information was collected from mandatory Swedish national registries. Morbidity and mortality, inpatient (admission and discharge dates, and main and secondary diagnoses) and outpatient hospital care (number of contacts and diagnoses according to ICD-10-CM codes) data were collected from the National Patient Register. Date and cause(s) of death were obtained from the Cause of Death Register. The Swedish Prescribed Drug Register was used to acquire data regarding drug prescriptions from hospital and primary care during the study period. Population data, such as number and gender distribution for each year of birth, as well as information regarding income, socioeconomic status, and education level were generated by Statistics Sweden (Statistiska Centralbyrån, Stockholm, Sweden).

The study was registered at ClinicalTrials.gov (clinical trial identifier NCT01146392) and reviewed and approved by the regional ethics committee in Uppsala, Sweden (reference number 2010/040). Patient consent was not required by the committee as all data was anonymized.

\section{Study population and outcome variables}

From the chosen primary care centers, men and women with physician-diagnosed COPD (ICD-10-CM code J44) in medical records or national registers were included in the study. Patients who had physician-diagnosed COPD any time from January 1, 1999, to December 31, 2009, were eligible for inclusion and the index date was defined as date of first COPD diagnosis. Patients were followed until December 31, 2009, emigration or death.

Lung cancer diagnoses (ICD-10 code C34) were obtained from medical records, the National Patient Registry, and the Cause of Death Register.

Comorbidities were analyzed in regard to ICD-10-CM diagnoses registered in medical records or national registers, and for patients with lung cancer before this diagnosis appeared in the register. The following comorbidities were included: asthma, hypertension, congestive heart failure, diabetes, myocardial infarction, osteoporosis, stroke, and depression.

Prescription events were analyzed for pack-size and prescribed daily dose related to predefined Anatomical 
Therapeutic Chemical Classification System groups. Data on use of medication were collected from the period 2 years prior to COPD diagnosis until the end of the observation period (December 31, 2009), emigration or death. To analyze any exposure-dependency, a relative exposure was calculated as the proportion of days covered of the drug of interest, during a time interval of at least 2 years (starting 2 years prior to index). Drug exposure was included as a time varying covariate updated once every year. The following drugs were included (Anatomical Therapeutic Chemical Classification System code[s]): ICS (R03BA); long-acting beta-2-agonists (LABA) (R03AC12 and R03AC13); long-acting muscarinic antagonists (LAMA) (R03BB) (which in all cases were tiotropium, as this was the only LAMA available during the observation period); NAC (R05CB); oral corticosteroids (H02AB); bisphosphonates (M05BA); statins (C10AA); acetylsalicylic acid (B01AC06); angiotensin-converting enzyme inhibitors (C09A and C09B), beta-blockers (C07); angiotensin II receptor blockers (C09C and C09D); diuretics (C03); and selective serotonin reuptake inhibitors (SSRI) (N06AB). Patients using fixed combinations of ICS and LABA (R03AK) were classified as users of both drugs separately. In the multivariable analyses, the exposure-dependent association was calculated with adjustment for any use of the drug.

Information on smoking habits was only available for $11.0 \%$ and lung function data for $12.0 \%$ of the total study population. Because of the limited number, no analyses on the effects of smoking and lung function are shown.

\section{Statistical analyses}

The risk of developing lung cancer was studied in regard to baseline covariates (age at COPD diagnosis, gender, asthma, education level, marital status, income prior to index, and time-dependent covariates medication and comorbidities).

The time to lung cancer was analyzed using a proportional hazards Cox model. The analyses were performed in two steps. In the first step, all risk factors were analyzed one by one. In the second step, all factors with a $p$-value below 0.2 were entered into a multivariate stepwise Cox model, where the final model was defined as the one with the lowest Akaike information criterion value. Descriptive analyses were also done comparing COPD patients who did or did not develop lung cancer.

\section{Results}

\section{Cohort characteristics}

Of the total cohort, 19,894 patients were included in this analysis and of these 594 lung cancer cases were diagnosed between 1999 and 2009, corresponding to $3.0 \%$ of the studied population.
Table I Demographic details and comorbidities for the patient cohort at the time of the COPD diagnosis ( $n(\%)$ and mean \pm SD)

\begin{tabular}{|c|c|c|c|}
\hline \multirow[t]{2}{*}{ Variables } & \multirow{2}{*}{$\frac{\text { Lung cancer }}{(\mathbf{N}=\mathbf{5 9 4 )}}$} & \multirow{2}{*}{$\frac{\text { No lung cancer }}{(\mathrm{N}=19,300)}$} & \multirow[t]{2}{*}{$p$-value } \\
\hline & & & \\
\hline Women & $303(51.0)$ & $10,139(52.5)$ & 0.48 \\
\hline Age & $68.9 \pm 8.5$ & $68.0 \pm 11.4$ & 0.08 \\
\hline Single & $122(27.1)$ & 4,93I (3I.4) & 0.06 \\
\hline Annual income $\times 1,000$ SEK & $139 \pm 95$ & $145 \pm 142$ & 0.44 \\
\hline Higher education level & 175 (38.9) & $7,259(46.2)$ & 0.002 \\
\hline Asthma & $6 \mathrm{I}(10.3)$ & $3,536(18.3)$ & $<0.001$ \\
\hline Hypertension & $109(18.4)$ & $4,457(23.1)$ & 0.006 \\
\hline Heart failure & $26(4.4)$ & $\mathrm{I}, 860(9.6)$ & $<0.001$ \\
\hline Myocardial infarction & $21(3.5)$ & $896(4.6)$ & 0.23 \\
\hline Stroke & $29(4.9)$ & $\mathrm{I}, \mathrm{I} 77(6 . \mathrm{I})$ & 0.26 \\
\hline Diabetes & $45(7.6)$ & $\mathrm{I}, 685(8.7)$ & 0.38 \\
\hline Osteoporosis & $15(2.5)$ & $517(2.7)$ & $>0.99$ \\
\hline Depression & $27(4.6)$ & I,752 (9.1) & $<0.001$ \\
\hline
\end{tabular}

Abbreviation: SEK, Swedish Krona.

Lung cancer patients had a lower average level of education than the non-cancer patients. There was no significant age or gender difference between patients who developed or did not develop lung cancer (Table 1).

Patients who developed lung cancer had a lower prevalence of asthma, hypertension, heart failure, and depression before the time of COPD diagnosis than those who did not develop lung cancer (Table 1).

\section{Factors influencing lung cancer risk - univariate analysis}

In univariate Cox regression analysis, age and education were the non-medical factors that were statistically significantly associated with an effect on the risk of developing lung cancer. COPD patients with asthma and depression diagnoses showed a reduced risk of lung cancer development (Table 2).

Table 2 The association between demographic variables and comorbidities with the risk of developing lung cancer assessed by univariate Cox regression

\begin{tabular}{llll}
\hline Variables & HR & $\mathbf{9 5 \% ~ C l ~}$ & $\mathbf{p}$-value \\
\hline Gender & $\mathrm{I} .10$ & $(0.93-1.29)$ & 0.27 \\
Age per 10 years & 1.22 & $(1.13-1.32)$ & $<0.00 \mathrm{I}$ \\
Single & 0.90 & $(0.73-1.1 \mathrm{I})$ & $0.3 \mathrm{I}$ \\
Income* & 1.00 & $(0.93-1.08)$ & 0.98 \\
Education (high vs low)* $^{*}$ & 0.74 & $(0.61-0.89)$ & 0.002 \\
Asthma & 0.54 & $(0.41-0.73)$ & $<0.00 \mathrm{I}$ \\
Hypertension & 1.03 & $(0.87-1.23)$ & 0.70 \\
Heart failure & 0.90 & $(0.73-1.12)$ & 0.35 \\
Myocardial infarction & 1.16 & $(0.88-1.53)$ & 0.30 \\
Stroke & 0.88 & $(0.66-1.17)$ & 0.38 \\
Diabetes & 1.00 & $(0.79-1.28)$ & 0.96 \\
Osteoporosis & 1.16 & $(0.84-1.60)$ & 0.630 \\
Depression & 0.71 & $(0.54-0.94)$ & 0.014 \\
\hline
\end{tabular}

Note: *Data available for 16,153 patients. 
Table 3 The association between use of medication and the risk of developing lung cancer assessed by univariate Cox regression

\begin{tabular}{|c|c|c|c|c|c|c|}
\hline \multirow[t]{2}{*}{ Variables } & \multicolumn{3}{|c|}{ Any use } & \multicolumn{3}{|c|}{ Relative exposure* } \\
\hline & HR & $95 \% \mathrm{Cl}$ & $p$-value & HR & $95 \% \mathrm{Cl}$ & $p$-value \\
\hline Inhaled corticosteroids** & 1.06 & $(0.89-1.26)$ & 0.54 & 0.75 & $(0.56-1.01)$ & 0.06 \\
\hline Long-acting beta-2-agonists*** & 1.14 & $(0.96-1.35)$ & 0.12 & 0.84 & $(0.6 I-I .15)$ & 0.27 \\
\hline Long-acting muscarinic antagonists & 1.60 & $(1.35-1.91)$ & $<0.001$ & 1.62 & $(1.22-2.15)$ & 0.001 \\
\hline $\mathrm{N}$-acetylcysteine & 1.48 & $(1.24-1.77)$ & $<0.001$ & 1.59 & $(1.15-2.19)$ & 0.005 \\
\hline Oral corticosteroids & 1.88 & $(1.59-2.22)$ & $<0.001$ & 1.49 & $(0.92-2.43)$ & 0.11 \\
\hline Statins & 0.87 & $(1.59-2.22)$ & 0.18 & 0.96 & $(0.66-1.39)$ & 0.83 \\
\hline Bisphosphonates & 1.19 & $(0.87-1.64)$ & 0.27 & 1.32 & $(0.60-2.88)$ & 0.49 \\
\hline ACE inhibitors & 0.90 & $(0.73-1.12)$ & 0.36 & 0.88 & $(0.57-1.35)$ & 0.55 \\
\hline Beta-blockers & 1.04 & $(0.87-1.25)$ & 0.63 & 1.02 & $(0.75-1.39)$ & 0.90 \\
\hline ARB & 1.00 & $(0.78-1.27)$ & 0.98 & 0.97 & $(0.62-1.50)$ & 0.88 \\
\hline SSRI & 0.79 & $(0.63-0.99)$ & 0.05 & 0.57 & $(0.34-0.97)$ & 0.04 \\
\hline Acetylsalicylic acid & 1.37 & $(1.15-1.63)$ & 0.02 & 1.68 & $(1.27-2.24)$ & $<0.001$ \\
\hline Diuretics & 1.21 & $(1.03-1.44)$ & 0.02 & 1.00 & $(0.74-1.35)$ & 0.99 \\
\hline
\end{tabular}

Notes: *Calculated as the proportion of days covered of the drug, during the study period. **Alone or together with long-acting beta-2-agonists. ***Alone or together with inhaled corticosteroids.

Abbreviations: ACE, angiotensin-converting enzyme; ARB, angiotensin II receptor blockers; SSRI, selective serotonin reuptake inhibitors.

Use of LAMA, NAC, and acetylsalicylic acid was associated with an increased risk of lung cancer. SSRI was associated with a decreased risk of lung cancer (Table 3). When medication was analyzed in regard to any exposure, but not taking accumulated exposure into account, LAMA, NAC, oral corticosteroids, acetylsalicylic acid, and diuretics had a significant association with an increased risk of lung cancer, whereas SSRI was associated with a decreased risk of lung cancer (Table 3).

\section{Factors influencing lung cancer risk - multivariate analysis}

Age was an independent risk factor for lung cancer, whereas patients with a concurrent asthma diagnosis had a decreased risk (Table 4). An exposure-dependent decreased lung cancer

Table 4 The independent association between demographic variables, comorbidities, and medication with the risk of developing lung cancer assessed by step wise Cox regression

\begin{tabular}{|c|c|c|c|}
\hline Variables & HR & $95 \% \mathrm{Cl}$ & $p$-value \\
\hline Age per 10 years & 1.18 & $(1.09-1.28)$ & $<0.001$ \\
\hline Asthma & 0.54 & $(0.4 I-0.7 I)$ & $<0.001$ \\
\hline Inhaled corticosteroids, relative exposure* & 0.52 & $(0.37-0.73)$ & $<0.001$ \\
\hline Oral corticosteroids, relative exposure* & 0.45 & $(0.22-0.90)$ & 0.02 \\
\hline Acetylsalicylic acid, relative exposure* & 1.58 & $(1.15-2.16)$ & 0.005 \\
\hline LAMA, any use & 1.41 & $(1.17-1.70)$ & $<0.001$ \\
\hline $\mathrm{N}$-acetylcysteine, any use & 1.31 & $(1.09-1.59)$ & 0.005 \\
\hline Oral corticosteroids, any use & 2.33 & $(1.89-2.87)$ & $<0.001$ \\
\hline SSRI, any use & 0.74 & $(0.59-0.96)$ & 0.008 \\
\hline Statins, any use & 0.76 & $(0.6 \mathrm{I}-0.96)$ & 0.02 \\
\hline
\end{tabular}

Note: *Calculated as the proportion of days covered of the drug, during the study period.

Abbreviations: LAMA, long-acting muscarinic antagonists; SSRI, selective serotonin reuptake inhibitors. risk was seen in patients using ICS and oral corticosteroids, whereas the opposite was found for the use of acetylsalicylic acid. Any use of LAMA, NAC, and oral corticosteroids was associated with a higher independent risk of lung cancer, while any use of SSRI and statins was associated with a decreased risk.

The exposure-dependent decreased risk of lung cancer with the use of ICS was seen regardless of whether the patients had a concurrent diagnosis of asthma or not (Figure 1).

\section{Discussion}

The main results of the present study in this large populationbased cohort of COPD patients were that COPD patients with coexistent asthma have a lower risk of developing lung cancer. The study also indicates that the patient's

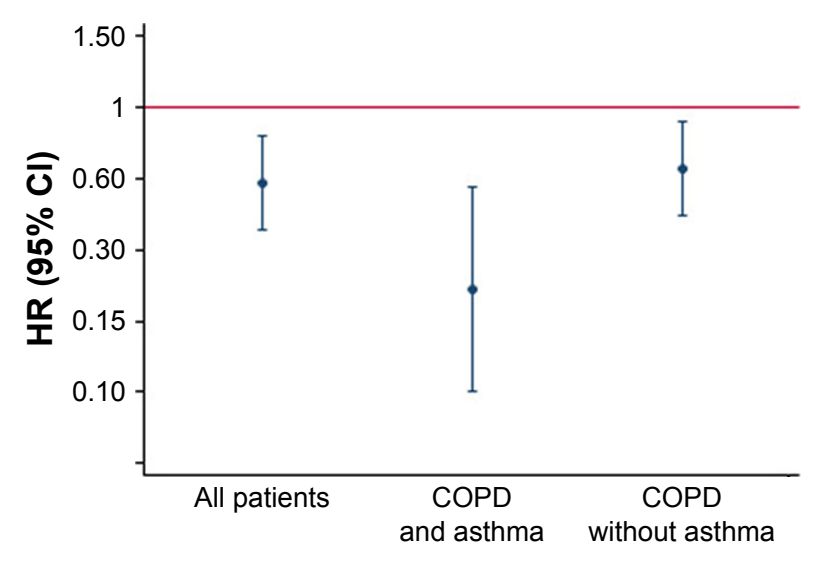

Figure I The independent association between the relative exposure (calculated as the proportion of days covered of the drug, during the study period) of inhaled corticosteroids and the risk of developing lung cancer assessed by step wise Cox regression in relation to having or not having concurrent asthma. 
pharmacological treatment may influence the risk of developing lung cancer, with ICS having a protective effect, and acetylsalicylic acid use increased the risk.

COPD patients, who were also diagnosed with asthma, had a lower risk of developing lung cancer. Data concerning lung cancer risk in asthma patients are contradictory. It has been suggested that an atopic constitution including asthma is linked to an increased risk of lung cancer. ${ }^{21,22}$ However, there is also evidence of a decreased risk, ${ }^{23}$ as well as studies where no relationship is confirmed. ${ }^{24}$ Our finding of a lower incidence of lung cancer in patients with COPD and asthma, compared to those with COPD only, is partly in accordance with a recent study where patients with ACO were found to have a similar prevalence of lung cancer as patients with asthma, despite an increased exposure to cigarette smoke in the ACO group. ${ }^{25}$ It is, however, possible that the group with both asthma and COPD in our study had smoked less than the group with only COPD. As we have no data on pack-years of smoking, this is something we cannot control for in this study.

In our analyses we interpreted that an exposure-dependent association between a pharmacological treatment and lung cancer may indicate a true association. On the other hand we assume that the association between any use of a drug, eg, NAC and LAMA, and lung cancer is probably related to the disease phenotype or comorbidities. In the present analyses there was an exposure-dependent association between use of ICS and a lower risk of lung cancer. This study therefore indicates that COPD patients using ICS had a decreased risk of developing lung cancer. That is in accordance with data from Parimon et al, who found that ICS were linked to a decreased risk of lung cancer in a COPD cohort. They hypothesized that this finding was associated with reduced airway inflammation resulting in decreased cell turnover, which in turn lowered the risk for propagation of genetic errors. ${ }^{11}$ A recent study showed that the airway remodeling of COPD patients was suppressed by ICS inhalations. Even though the study was only a small proof-of-concept study, the epithelial-mesenchymal transition was significantly reduced in the ICS group, indicating that the pro-malignant process was at least delayed. ${ }^{26}$ It is important to note that the negative association between the use of ICS and lung cancer in the present study was seen regardless of whether the patients were diagnosed with concurrent asthma or not.

We found a significant exposure-related association between the use of acetylsalicylic acid and increased lung cancer risk. In a large, recently published meta-analysis, including almost 20,000 lung cancer cases, no explicit association between acetylsalicylic acid and lung cancer risk was found. ${ }^{14}$ In previous studies, acetylsalicylic acid has been shown to reduce risk in a variety of non-lung cancers, ${ }^{27-29}$ but reports on lung cancer risk per se have varied from no significant correlation ${ }^{27}$ to a reduction, ${ }^{30-32}$ as well as an increased risk. ${ }^{33,34} \mathrm{We}$ included only COPD patients in our study, which is not the case in other studies. Whether COPD affects the suggested mechanism of acetylsalicylic acid risk reduction or not is still to be determined, and further studies are needed to answer that question.

There was no significant exposure-response relationship between the use of NAC and lung cancer risk in the present study. NAC has anti-oxidative features that are used in the treatment of interstitial pulmonary fibrosis. ${ }^{35}$ Recent research has pointed toward a new and potentially detrimental role for anti-oxidants in cancer development. The previously widely adopted view that reactive oxygen species were linked to cancer development and progression, has been questioned by findings that the treatment of mice with anti-oxidants actually increases the risk for lung cancer development. ${ }^{13}$ The present study, however, does not support such association in humans. Further, there was no significant exposure-response relationship between the use of LAMA and lung cancer risk. This result is in accordance with that of the UPLIFT trial, which reported no additive risk of lung cancer for patients using tiotropium. ${ }^{36}$

The risk-reducing effect of statins in multiple tumors was confirmed by a recent meta-analysis, ${ }^{37}$ although the authors agree that there is significant heterogeneity among the studies they included. We found no exposure-dependent risk reduction in our study related to statins. It is likely that the reduced non-exposure-dependent risk seen in our study for patients who are exposed to statins is due to confounding factors we did not adjust for, such as higher rates of smoking cessation or more frequent health assessments in relation to cardiovascular disease.

\section{Limitations}

Our study has several limitations. The most important limitations were that smoking and lung function could not be assessed in more than a small proportion of the cohort, and was therefore not included in the analyses. Another is that we lack data on pharmacological treatment before 2005 and that the observational period does not cover recent years, thereby not capturing potential changes in COPD management. However, the present study is based on large populationbased COPD data likely to reflect most western populations in its constitution of socioeconomic and educational levels. 
The Swedish health care and social system with personal identification number enables a unique cross-matching of registries providing in-depth knowledge of individual data with almost complete coverage of many parameters such as comorbidity, medication, cause of hospital visits and stays, socioeconomic factors, and survival data.

\section{Conclusion}

This study shows that a concurrent diagnosis of asthma and the use of ICS was independently related to decreased risk of lung cancer risk in COPD patients, while the use of acetylsalicylic acid was associated with an increased risk. COPD represents the third most common cause of death and lung cancer the most common cancer-related death globally. While there is strong inter-correlation between these two diseases, the need to understand additive risks, as well as protective factors, is important. The finding in the present study that pharmacological treatment may modify the risk relation between these two diseases should be seen as hypothesis generating and needs to be confirmed in prospective studies.

\section{Acknowledgments}

This study was sponsored by AstraZeneca.

\section{Disclosure}

Martin Sandelin has received honoraria for lectures from AstraZeneca, Novartis, Boehringer Ingelheim, and Amirall and has received grants from the Professor John Naeslunds Stipendiefond, Ture Stenholms Minnesfond and Uppsala County Association Against Heart and Lung Diseases. Karin Lisspers has received honoraria for educational activities and lectures from AstraZeneca, GlaxoSmithKline, Novartis, MEDA, and Takeda and has served on advisory boards arranged by MEDA and Novartis. Kjell Larsson has, during the last 5 years, on one or more occasion served on an advisory board, served as a speaker, and/or participated in education arranged by AstraZeneca, Boehringer Ingelheim, GlaxoSmithKline, Takeda, Novartis, Chiesi, Orion, and TEVA. Gunnar Johansson has served on advisory boards arranged by Astra Zeneca, Novo Nordisk, and Takeda. Christer Janson has received honoraria for educational activities and lectures from Novartis, AstraZeneca, GlaxoSmithKline, and Boehringer Ingelheim outside the submitted work. Björn Ställberg has received honoraria for educational activities and lectures from AstraZeneca, Boehringer Ingelheim, GlaxoSmithKline, Novartis, MEDA, and TEVA and has served on advisory boards arranged by AstraZeneca, Novartis, GSK, Boehringer Ingelheim, TEVA, and MEDA. The authors report no other conflicts of interest in this work.

\section{References}

1. Teramoto S. 1. COPD pathogenesis from the viewpoint of risk factors. Intern Med. 2007;46(2):77-79.

2. Sorheim IC, Johannessen A, Gulsvik A, et al. Gender differences in COPD: are women more susceptible to smoking effects than men? Thorax. 2010;65(6):480-485.

3. Houghton AM. Mechanistic links between COPD and lung cancer. Nat Rev Cancer. 2013;13(4):233-245.

4. Stallberg B, Janson C, Johansson G, et al. Management, morbidity and mortality of COPD during an 11-year period: an observational retrospective epidemiological register study in Sweden (PATHOS). Prim Care Respir J. 2014;23(1):38-45.

5. Mannino DM, Aguayo SM, Petty TL, Redd SC. Low lung function and incident lung cancer in the United States: data From the First National Health and Nutrition Examination Survey follow-up. Arch Intern Med. 2003;163(12):1475-1480.

6. Church DF, Pryor WA. Free-radical chemistry of cigarette smoke and its toxicological implications. Environ Health Perspect. 1985;64: 111-126.

7. Goldkorn T, Filosto S, Chung S. Lung injury and lung cancer caused by cigarette smoke-induced oxidative stress: Molecular mechanisms and therapeutic opportunities involving the ceramide-generating machinery and epidermal growth factor receptor. Antioxid Redox Signal. 2014;21(15):2149-2174.

8. Turner MC, Chen Y, Krewski D, Calle EE, Thun MJ. Chronic obstructive pulmonary disease is associated with lung cancer mortality in a prospective study of never smokers. Am J Respir Crit Care Med. 2007;176(3):285-290.

9. Brenner DR, Boffetta P, Duell EJ, et al. Previous lung diseases and lung cancer risk: a pooled analysis from the International Lung Cancer Consortium. Am J Epidemiol. 2012;176(7):573-585.

10. de Torres JP, Bastarrika G, Wisnivesky JP, et al. Assessing the relationship between lung cancer risk and emphysema detected on low-dose CT of the chest. Chest. 2007;132(6):1932-1938.

11. Parimon T, Chien JW, Bryson CL, et al. Inhaled corticosteroids and risk of lung cancer among patients with chronic obstructive pulmonary disease. Am J Respir Crit Care Med. 2007;175(7):712-719.

12. Lee $\mathrm{CH}$, Hyun MK, Jang EJ, et al. Inhaled corticosteroid use and risks of lung cancer and laryngeal cancer. Respir Med. 2013;107(8): 1222-1233.

13. Sayin VI, Ibrahim MX, Larsson E, et al. Antioxidants accelerate lung cancer progression in mice. Sci Transl Med. 2014;6(221):221ra15.

14. Jiang HY, Huang TB, Xu L, et al. Aspirin use and lung cancer risk: a possible relationship? Evidence from an updated meta-analysis. PLoS One. 2015;10(4):e0122962.

15. Lisspers K, Johansson G, Jansson C, et al. Improvement in COPD management by access to asthma/COPD clinics in primary care: data from the observational PATHOS study. Respir Med. 2014;108(9): 1345-1354.

16. Soler-Cataluna JJ, Cosio B, Izquierdo JL, et al. Consensus document on the overlap phenotype COPD-asthma in COPD. Archiv Bronconeumol. 2012;48(9):331-337.

17. Chatila WM, Thomashow BM, Minai OA, Criner GJ, Make BJ. Comorbidities in chronic obstructive pulmonary disease. Proc Am Thorac Soc. 2008;5(4):549-555.

18. Vanfleteren LE, Spruit MA, Groenen M, et al. Clusters of comorbidities based on validated objective measurements and systemic inflammation in patients with chronic obstructive pulmonary disease. Am J Respir Crit Care Med. 2013;187(7):728-735. 
19. Zhang MW, Ho RC, Cheung MW, Fu E, Mak A. Prevalence of depressive symptoms in patients with chronic obstructive pulmonary disease: a systematic review, meta-analysis and meta-regression. Gen Hosp Psychiatry. 2011;33(3):217-223.

20. Martinell M, Stalhammar J, Hallqvist J. Automated data extraction - a feasible way to construct patient registers of primary care utilization. Ups J Med Sci. 2012;117(1):52-56.

21. Santillan AA, Camargo CA Jr, Colditz GA. A meta-analysis of asthma and risk of lung cancer (United States). Cancer Causes Control. 2003; 14(4):327-334.

22. Gorlova OY, Zhang Y, Schabath MB, et al. Never smokers and lung cancer risk: a case-control study of epidemiological factors. Int $J$ Cancer. 2006;118(7):1798-1804.

23. El-Zein M, Parent ME, Ka K, et al. History of asthma or eczema and cancer risk among men: a population-based case-control study in Montreal, Quebec, Canada. Ann Allergy Asthma Immunol. 2010;104(5): 378-384.

24. Ramanakumar AV, Parent ME, Menzies D, Siemiatycki J. Risk of lung cancer following nonmalignant respiratory conditions: evidence from two case-control studies in Montreal, Canada. Lung Cancer. 2006; 53(1):5-12.

25. Harada T, Yamasaki A, Fukushima T, et al. Causes of death in patients with asthma and asthma-chronic obstructive pulmonary disease overlap syndrome. Int J Chron Obstruct Pulm Dis. 2015;10:595-602.

26. Sohal SS, Soltani A, Reid D, et al. A randomized controlled trial of inhaled corticosteroids (ICS) on markers of epithelial-mesenchymal transition (EMT) in large airway samples in COPD: an exploratory proof of concept study. Int J Chron Obstruct Pulm Dis. 2014;9: 533-542.

27. Jacobs EJ, Thun MJ, Bain EB, et al. A large cohort study of long-term daily use of adult-strength aspirin and cancer incidence. J Natl Cancer Inst. 2007;99(8):608-615.
28. Ishikawa H, Wakabayashi K, Suzuki S, et al. Preventive effects of low-dose aspirin on colorectal adenoma growth in patients with familial adenomatous polyposis: double-blind, randomized clinical trial. Cancer Med. 2013;2(1):50-56.

29. Ye X, Fu J, Yang Y, et al. Frequency-risk and duration-risk relationships between aspirin use and gastric cancer: a systematic review and meta-analysis. PLoS One. 2013;8(7):e71522.

30. Khuder SA, Herial NA, Mutgi AB, Federman DJ. Nonsteroidal antiinflammatory drug use and lung cancer: a metaanalysis. Chest. 2005 ; 127(3):748-754.

31. McCormack VA, Hung RJ, Brenner DR, et al. Aspirin and NSAID use and lung cancer risk: a pooled analysis in the International Lung Cancer Consortium (ILCCO). Cancer Causes Control. 2011;22(12): 1709-1720.

32. Lim WY, Chuah KL, Eng P, et al. Aspirin and non-aspirin non-steroidal anti-inflammatory drug use and risk of lung cancer. Lung Cancer. 2012;77(2):246-251.

33. Feskanich D, Bain C, Chan AT, et al. Aspirin and lung cancer risk in a cohort study of women: dosage, duration and latency. Br J Cancer. 2007;97(9):1295-1299.

34. Hernandez-Diaz S, Garcia Rodriguez LA. Nonsteroidal anti-inflammatory drugs and risk of lung cancer. Int J Cancer. 2007;120(7) 1565-1572.

35. Meyer A, Buhl R, Magnussen H. The effect of oral N-acetylcysteine on lung glutathione levels in idiopathic pulmonary fibrosis. Eur Respir J. 1994;7(3):431-436.

36. Celli B, Decramer M, Kesten S, et al. Mortality in the 4-year trial of tiotropium (UPLIFT) in patients with chronic obstructive pulmonary disease. Am J Respir Crit Care Med. 2009;180(10):948-955.

37. Zhong S, Zhang X, Chen L, et al. Statin use and mortality in cancer patients: systematic review and meta-analysis of observational studies. Cancer Treat Rev. 2015;41(6):554-567.
International Journal of COPD

\section{Publish your work in this journal}

The International Journal of COPD is an international, peer-reviewed journal of therapeutics and pharmacology focusing on concise rapid reporting of clinical studies and reviews in COPD. Special focus is given to the pathophysiological processes underlying the disease, intervention programs, patient focused education, and self management protocols.

\section{Dovepress}

This journal is indexed on PubMed Central, MedLine and CAS. The manuscript management system is completely online and includes a very quick and fair peer-review system, which is all easy to use. Visit http://www.dovepress.com/testimonials.php to read real quotes from published authors. 